\title{
Quantitative Assessment of Distributed Generation Benefits to Improve Power System Indices
}

\author{
Mehdi S. Naderi ${ }^{1}$, Mohammad S. Naderi ${ }^{2}$, K. Rahmani ${ }^{3}$, G.B. Gharehpetian ${ }^{1,3}$, L. Zahedi ${ }^{3}$ \\ ${ }^{1}$ Iran Grid Secure Operation Research Centre (IGSORC) \\ ${ }^{3}$ Department of Electrical Engineering \\ Amirkabir University of Technology (AUT), \\ Tehran, Iran \\ Phone/Fax number: +98 21664055854 \\ E-mail: salaynaderi@aut.ac.ir, koorosh_rahmani@yahoo.com, grptian@aut.ac.ir, 1.zahedi@aut.ac.ir
}

\author{
Mohammad S. Naderi \\ ${ }^{2}$ School of Electrical Engineering and Telecommunications \\ University of New South Wales (UNSW) \\ Sydney, Australia
}

Phone/Fax number: +61 29385 5262/5993, e-mail:m.salaynaderi@unsw.edu.au

\begin{abstract}
In this paper, a novel approach is proposed to assess and quantifying some of the technical benefits of Distributed Generation (DG) based on a set of indices. The proposed indices are: Voltage Profile Improvement index, Network Loss Reduction index, Line Capacity Release index and Greenhouse Gases Effect Reduction index. The Zanjan Regional Electric Company (ZREC) power system network has been simulated by DIgSILENT software and proposed indices have been determined in different scenarios. These scenarios have been developed considering the number of busses with DG connection, geographically dispersed substations with installed DGs and the capacity of the installed DG. The study results have been presented and discussed to illustrate quantitatively usefulness of utilizing distributed generation technologies in bulk power system.
\end{abstract}

\section{Key words}

Distributed generation, Quantitative assessment, Voltage profile, Line losses, Line capacity release, Greenhouse effect

\section{INTRODUCTION}

With present electric sector regulations that allow independent energy producers to access transmission and distribution systems, the presence of customers with energy exportation capabilities and, moreover, governments' incentives for specific energy resources, distributed generation (DG) appears to have many factors supporting its rapid development [1]. DG can be powered by both conventional and renewable energy sources [1,2].

Distributed generations (DG) is related with the use of small generating units installed in strategic points of the electric power system and, mainly, closes to load centers. The technologies applied in DG comprise small gas turbines, micro-turbines, fuel cells, wind and solar energy, etc. DG can be used in an isolated way, supplying the consumer's local demand, or in an integrated way, supplying energy to the remaining of the electric system [3].

Most of the benefits of employing DG in existing distribution networks have both economic and technical implications and they are interrelated. As such, it is proposed to classify the benefits into two groups technical and economic.

The major technical benefits are:

- Reduced line losses

- Voltage profile improvement

- Reduced emissions of pollutants

- Increased overall energy efficiency

- Enhanced system reliability and security

- Improved power quality

- Relieved T\&D congestion

The major economic benefits are:

- Deferred investments for upgrades of facilities

- Reduced O\&M costs of some DG technologies

- Enhanced productivity

- Reduced health care costs due to improved environment

- Reduced fuel costs due to increased overall efficiency

- Reduced reserve requirements and the associated costs

- Lower operating costs due to peak shaving

- Increased security for critical loads

Chiradeja in [4] has quantified the benefit of reduced line loss in a radial distribution feeder with concentrated load. A line loss reduction analysis is shown clearly in [5]. The loss can be significant under heavy load conditions. The utility is forced to pass the cost of electrical line losses to all customers in terms of higher energy cost. With the inclusion of DG, line loss in the distribution system can be reduced.

The limit of [5] is only to search the line loss reduction for the simplest case of a radial distribution feeder. In fact, the utility networks are more complex, they usually have a radial structure with many feeders along the transmission line.

The benefits of DG have discussed by evaluating and quantifying in terms of capacity credit, energy value and energy cost saving in[6]. The effects of improvement in voltage profile and loss reduction were not considered in the method. Joss et al. [7] have demonstrated the potential of DG with power electronic interface to provide ancillary services such as reactive power, voltage sag compensation and harmonic filtering. It has proved the ability of DG to compensate voltage sag resulting from faults in the power 
system. However the method did not analyze the amount of power loss reduction due to DG installation.

In light of the well-known benefits as well as the various issues involved in DG in corporation, proposes different indices [8]. By introducing DG in the system, voltage profile can be improved because DG can provide a portion of the real and reactive power to the load, thus helping to decrease current along a section of the distribution line, which, in turn, will result in a boost in the voltage magnitude at the customer site. The primal dual interior point (PDIP) method has been employed to identify the optimal location and real and reactive power generation on the basis of the newly proposed indices.

This paper presents a methodology to evaluate the impact of DG units installation on voltage profile improvement, line loss reduction, line capacity release and the greenhouse gases effect of distribution networks. The influence of the local of installation and the capacity of DG on these system performance characteristics will be shown for different generation expansion planning alternatives using the proposed methodology.

\section{DEFINITION OF INDICES TO QUANTIFY THE BENEFITS OF DG}

In order to evaluate and quantify the benefits of distributed generation technologies, suitable mathematical models along with distribution system models should be employed to run power flow calculations to arrive at indices of benefits. Among the many benefits, four major ones are considered: Voltage profile improvement, line loss reduction, line voltage stability and greenhouse gases effects reduction.

\section{A. Voltage Profile Improvement Index(VPII)}

DG installation normally results in improved voltage profile at various buses. The Voltage Profile Improvement Index quantifies the improvement in the voltage profile (VP) with the inclusion of DG [8,9]. It is expressed as,

$$
V P I I=V P_{W / D G} / V P_{W O / D G}
$$

Based on this definition, the following attributes are:

VPII $<1$, DG has not beneficial,

$\mathrm{VPII}=1$, DG has no impact on the system voltage profile and

VPII > 1 DG has improved the voltage profile of the system.

Where, VPw/DG, VPwo/DG are the calculated amounts of the voltage profile of system substations with and without DG, respectively. The general expression for VP is given as,

$$
V P=\sum_{i=1}^{N} V_{i} L_{i} K_{i} \quad \text { with } \sum_{i=1}^{N} K_{i}=1
$$

Where, $\mathrm{Vi}$ is voltage magnitude at bus $\mathrm{i}$ in per unit, $\mathrm{Li}$ is load represented as complex bus power at bus $\mathrm{i}$ in per unit, $\mathrm{Ki}$ is weighting factor for bus $\mathrm{i}$, and $\mathrm{N}$ is total number of buses in the distribution system. Weighting factors are chosen based on the significance of different loads. As defined, the expression for VP provides an opportunity to quantify and aggregate the importance, amounts, and voltage levels at which loads are being supplied at various load busses in the system. This expression should be used only after making sure that the voltages at all the load busses are within allowable minimum and maximum limits, typically between 0.95 p.u. and 1.05 p.u. Starting with a set of equal weighting factors, modifications can be implemented. Acceptable voltage profile can be selected after analyzing the simulation results which are repeatedly conducted after each weighting factor modification. It should be noted that if all load busses are equally weighted, the value of $\mathrm{Ki}$ is given as below:

$$
K_{1}=K_{2}=\cdots=K_{N}=1 / N
$$

In this case, all the load buses are given equal importance. In reality, DG can be installed almost anywhere in the system.

In general, the highest value of VPII implies the best location for installing DG in terms of improving voltage profile. The voltage profile expression in (4) recognizes the influences of the amount and importance of load at each bus. It allows the possibility of a low-load bus with important load to have a strong impact. In general, weighting factors are assigned based on the importance/criticality of load at each bus.

\section{B. Line Loss Reduction Index}

Another major benefit offered by installation of DG is the reduction in electrical line losses [10]. By installing DG, line currents can be reduced, thus helping to reduce electrical line losses. The proposed line loss reduction index (LLRI) is defined as follow:

$$
L L R I=L L_{W / D G} / L L_{W O / D G}
$$

Where, LLw/DG is total line losses in the system with the employment of DG and LLwo/DG is total line losses in the system without DG and it can be calculated as below:

$$
L L_{W / D G}=3 \times \sum_{i=1}^{M} I_{i}^{2} \times R \times D_{i}
$$

Where, Ii is per unit line current in distribution line $\mathrm{i}$ with the employment of DG, R is line resistance (p.u. $/ \mathrm{km}$ ), Di is distribution line length $(\mathrm{km})$, and $\mathrm{M}$ is number of lines in the system. LLwo/DG is expressed similarly for the reference case.

Based on this definition:

LLRI $<1$ DG has reduced electrical line losses,

LLRI = 1 DG has no impact on system line losses,

LLRI > 1 DG has caused more electrical line losses. 
This index can be used to identify the best location to install DG which maximizes line loss reduction. Obviously, minimum value of LLRI corresponds to the best DG location scenario in terms of line loss reduction.

\section{Line Capacity Release Index (LCRI)}

One of the major benefits achieved by DG installation is line capacity release. As it mentioned, by installing DGs, line currents can be reduced. Consequently, loading of each line will be reduced and in another word, line capacity will release. The main advantage of line capacity release is postponing the power system network expansion and investment. LCRI concept is equal to line loading reduction concept; therefore, in this study the second concept has been calculated and presented.

\section{Greenhouse Gases Effect Reduction (GGER)}

The need for improving energy efficiency and reducing air emissions and other pollutants has favored the increase of DG utilization [12]. This is due to the increased awareness of pollution of the emission from fossil-fuel power station, which has led to the commitment of many countries to comply with the Kyoto Protocol and reduce green house gas (GHG) emissions. GHGs are gases in an atmosphere that absorb and emit radiation within the thermal infrared range. This process is the fundamental cause of the greenhouse effect. An emission performance standard is a limit that sets thresholds above which a different type of emission control technology might be needed. While emission performance standards have been used to dictate limits for conventional pollutants such as oxides of nitrogen and oxides of sulfur (NOx and SOx) and particularly carbon dioxide (CO2). In this study, the average decrement amounts of GHGs emission by substitution of present power plants with DGs are calculated.

\section{RESULTS AND DISCUSSIONS}

The study has been conducted on substations of entire transmission network of Iran including Zanjan Regional Electric Company (ZREC) transmission and subtransmission network with approved power system plans up to 2011. The defined parameters are calculated only for ZREC transmission and sub-transmission networks. Because of the sub-transmission network simulation of ZREC, loads of the transmission substations in ZREC are zero. The power system network is simulated in DIgSILENT software environment.

Different cases are defined based on the following consideration:

- Difference in the number and total load of selected substations for DGs to be installed

- Scattering of substations which DGs are installed

According to the above considerations, 3 cases are considered as below:

In case 1, 10 substations among ZREC substations are selected and in term of diversity, all of them are near together.
In case 2, 20 substations among ZREC substations are selected. Similar to the case 1 , substations are near together but the number of substations is twice.

In case 3, 20 substations among ZREC substations are selected. The number of substations is similar to the case 2 , but substations are quite far from each other.

Table I indicates summery of the introduced cases. In each case, 3 scenarios are considered. In all scenarios, installed DGs on the selected buses are proportional to the substation load.

The scenarios in each case are defined as below:

Scenario 1: $10 \%$ of the selected buses loads in ZREC are compensated by DGs.

Scenario 2: $20 \%$ of the selected buses loads in ZREC are compensated by DGs.

Scenario 3: 50\% of the selected buses loads in ZREC are compensated by DGs.

The reference scenario is ZREC power system network without any installed DG.

\section{TABLE I. SUMMERY OF THE CONSIDERED CASES}

\begin{tabular}{|c|c|c|c|}
\hline Cases & $\begin{array}{c}\text { No. of } \\
\text { selected } \\
\text { buses }\end{array}$ & $\begin{array}{c}\text { Total load on } \\
\text { selected } \\
\text { buses }\end{array}$ & $\begin{array}{c}\text { Dispersion of } \\
\text { selected buses }\end{array}$ \\
\hline Case 1 & 10 & 262 & Low \\
\hline Case 2 & 20 & 701 & Low \\
\hline Case 3 & 20 & 632 & High \\
\hline
\end{tabular}

\section{A. Impact of DG Installation on voltage profile improvement of the system}

In Fig. 1, the bar graph of voltage profile improvement index for various scenarios in each case is depicted. Also, to represent the exact values of VPII the calculated amounts are presented in Table II, for each scenario. VPII for the base case is considered 1.0 and for defined scenarios are calculated and divided to VP as expressed in (1). As it can be seen, in all cases, VPII has been improved by connecting DGs in selected substations. Comparing the case 1 scenarios with two other cases' scenarios, it can be concluded that increasing the number of buses to connect DGs has positive effect on VPII increment; especially while more loads are supplied by DGs. Also, by comparing cases 2 and 3 scenarios, it can be seen that selecting the buses with more dispersion in a region will increase voltage profile improvement index. It is clear that increasing the amount of generation by DGs, improves VPII considerably.

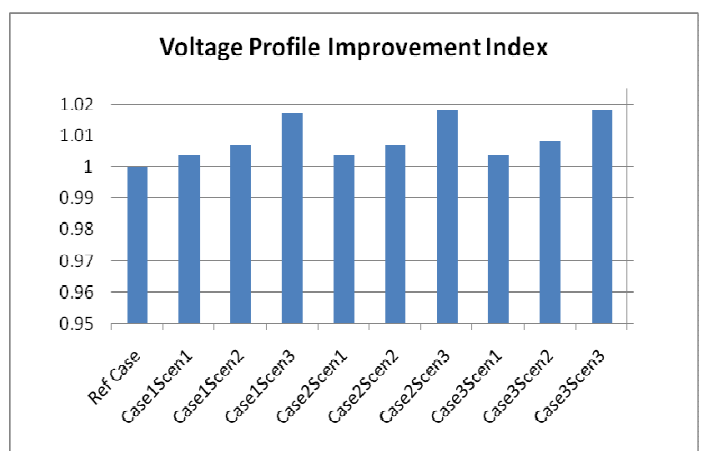

Fig. 1. Bar graph of VPII index for defined scenarios 
Table II. Quantitaive results of VPII for defined scenarios

\begin{tabular}{|c|l|c|c|}
\hline \multirow{3}{*}{ Cases } & Scenarios & VPII & $\begin{array}{c}\text { Improvement } \\
(\mathbf{\%})\end{array}$ \\
\cline { 2 - 4 } & Base Case & 1.000 & - \\
\hline \multirow{3}{*}{ Case 1 } & Scenario 1 & 1.004 & 0.4 \\
\cline { 2 - 4 } & Scenario 2 & 1.007 & 0.7 \\
\cline { 2 - 4 } & Scenario 3 & 1.017 & 1.7 \\
\hline \multirow{3}{*}{ Case 2 } & Scenario 1 & 1.004 & 0.4 \\
\cline { 2 - 4 } & Scenario 2 & 1.007 & 0.7 \\
\cline { 2 - 4 } & Scenario 3 & $\mathbf{1 . 0 1 8}$ & $\mathbf{1 . 8}$ \\
\hline \multirow{3}{*}{ Case 3 3} & Scenario 1 & 1.004 & 0.4 \\
\cline { 2 - 4 } & Scenario 2 & 1.008 & 0.8 \\
\cline { 2 - 4 } & Scenario 3 & $\mathbf{1 . 0 1 8}$ & $\mathbf{1 . 8}$ \\
\hline
\end{tabular}

\section{B. Results of DG Installation on line loss reduction of the system}

In Fig. 2 the bar graph of line loss reduction index for various scenarios is depicted. Table III indicates that for the various cases considered, the values of the line loss index of the system have been reduced by connecting a DG of various capacities. According to (4), for each scenario, line loss is divided to base case line loss value. Comparing the case 1 scenarios with cases 2 and 3 scenarios, it can be seen that increasing the number of buses to connect DGs has positive effect on LLRI. Also, by comparing the scenarios of the cases 2 and 3 , it can be concluded that selecting the buses with more dispersion in a region will decrease LLRI. It can be seen clearly that line loss reduction is proportional to the increasing of the generation by DGs.

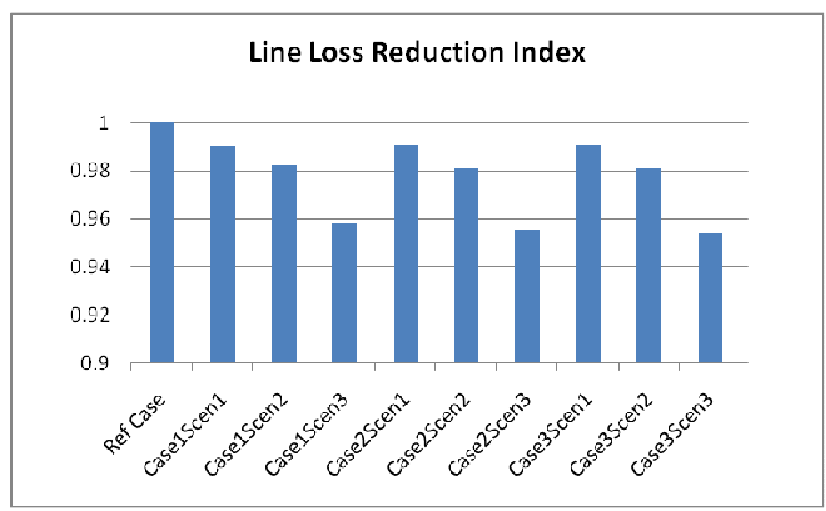

Fig. 2. Bar graph of LLRI for defined scenarios

Table III. Quantitative results of LLRI for defined scenarios

\begin{tabular}{|c|c|c|c|}
\hline \multirow{3}{*}{ Cases } & Scenarios & LLRI & $\begin{array}{c}\text { Improvement } \\
(\boldsymbol{\%})\end{array}$ \\
\cline { 2 - 4 } & Base Case & 1.000 & - \\
\hline \multirow{3}{*}{ Case 1 } & Scenario 1 & 0.9900 & 1 \\
\cline { 2 - 4 } & Scenario 2 & 0.9822 & 1.78 \\
\cline { 2 - 4 } & Scenario 3 & 0.9583 & 4.17 \\
\hline \multirow{3}{*}{ Case 2 } & Scenario 1 & 0.9904 & 0.96 \\
\cline { 2 - 4 } & Scenario 2 & 0.9809 & 1.91 \\
\cline { 2 - 4 } & Scenario 3 & 0.9555 & 4.45 \\
\hline \multirow{3}{*}{ Case 3 } & Scenario 1 & 0.9903 & 0.97 \\
\cline { 2 - 4 } & Scenario 2 & 0.9807 & 1.93 \\
\cline { 2 - 4 } & Scenario 3 & $\mathbf{0 . 9 5 4 0}$ & 4.6 \\
\hline
\end{tabular}

\section{Results of DG Installation on line capacity release index of the system}

In Fig. 3, bar graph of LCRI in terms of line loading percentage is depicted. As it over mentioned, decrement of line loading percentage equals to the increment of line capacity release index, as each conductor is capable to transfer certain level of MVA. Similar to other indices, quantitative results of line loading percentage which is in contrary with LCRI are indicated in Table IV. For this index, results show that increasing bus numbers that DGs are connected will increase line loading. Consequently, selecting less numbers of substations to install DGs improves LCRI. From the amount of generation point of view, as it is clear from Table IV, line loading percentage decreases with increment of DGs generation capacity. Therefore, LCRI increment is proportional to DGs generation capacity increment.

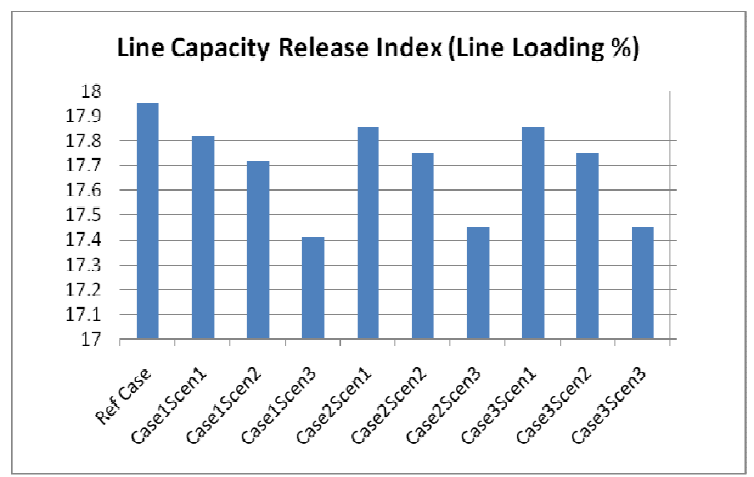

Fig. 3. Bar graph of LCRI index for defined scenarios

Table IV. Quantitative results of LCRI in contrary with line loading for defined scenarios

\begin{tabular}{|c|c|c|c|}
\hline \multirow{3}{*}{ Cases } & Scenarios & $\begin{array}{c}\text { Line } \\
\text { loading }(\boldsymbol{\%})\end{array}$ & $\begin{array}{c}\text { Improvement } \\
(\mathbf{\%})\end{array}$ \\
\cline { 2 - 4 } & Base Case & 17.95 & - \\
\hline \multirow{3}{*}{ Case 1 } & Scenario 1 & 17.82 & 0.72 \\
\cline { 2 - 4 } & Scenario 2 & 17.72 & 1.28 \\
\cline { 2 - 4 } & Scenario 3 & 17.41 & $\mathbf{3 . 0 1}$ \\
\hline \multirow{3}{*}{ Case 2 } & Scenario 1 & 17.85 & 0.56 \\
\cline { 2 - 4 } & Scenario 2 & 17.75 & 1.11 \\
\cline { 2 - 4 } & Scenario 3 & 17.45 & $\mathbf{2 . 7 9}$ \\
\hline \multirow{3}{*}{ Case 3 } & Scenario 1 & 17.85 & 0.56 \\
\cline { 2 - 4 } & Scenario 2 & 17.75 & 1.11 \\
\cline { 2 - 4 } & Scenario 3 & 17.45 & $\mathbf{2 . 7 9}$ \\
\hline
\end{tabular}

\section{Results of DG Installation on GHG effects reduction}

According to Iran ministry of energy reports on 2007, average amounts of GHGs emission by existing power plants are $0.973(\mathrm{gr} / \mathrm{kWh})$ for NOx, 2.694 $(\mathrm{gr} / \mathrm{kWh})$ for Sox and $643.872(\mathrm{gr} / \mathrm{kWh})$ for $\mathrm{CO} 2$ (Table V). On the other hand, average amount of GHGs emission by gas turbine and reciprocal engines is 0.000522 , negligible and 464.48 grammas per $\mathrm{kWh}$ for $\mathrm{NOx}$, Sox and $\mathrm{CO} 2$, respectively [13]. Therefore, decreasing rate of NOx, SOx and CO2 emission by generating electric power using DGs would be $0.972,2.694$ and 179.392 grammas per $\mathrm{kWh}$, respectively. Supposing 8 hours operation of DGs per day, total generation of DGs for defined scenarios in each case can be obtained as indicated in Table VI and consequently average decreased amount of GHGs emissions for one year would be as represented in Table VI. As it over mentioned, DGs are installed close to the load point. Therefore, because of line loss reduction, necessity of 
generating electric power by conventional power plants will be reduced. Table VII indicates reduced amounts of line loss for different scenarios of the case 3 and corresponding reduction of GHGs emission in one year. Total average amounts of GHGs emission corresponding to different scenarios of the case 3 for one year has been presented in Table VIII. As it can be seen by substituting only $132 \mathrm{MW}$ conventional electric power generations by DGs, emission of 84145 ton CO2, 1263 ton NOx and 455 ton SOx will be prevented in each year which are considerably high amounts.

Table V. Average amounts of GHGs emission by existing power plants and DGs

\begin{tabular}{|c|c|c|}
\hline GHG & $\begin{array}{l}\text { Avg. amount of } \\
\text { GHG emission by } \\
\text { existing PPs } \\
\text { (gr/kWh) }\end{array}$ & $\begin{array}{l}\text { Avg. amount of } \\
\text { GHG emission by } \\
\text { existing DGs } \\
\text { (gr/kWh) }\end{array}$ \\
\hline $\mathrm{NO}_{\mathrm{X}}$ & 0.973 & 0.000522 \\
\hline $\mathrm{SO}_{\mathrm{X}}$ & 2.694 & - \\
\hline $\mathrm{CO}_{2}$ & 643.872 & 464.48 \\
\hline
\end{tabular}

\section{CONCLUSION}

The penetration of DG in a distribution system offers several benefits to line capacity release losses, improved system voltage profile, reduced environmental impacts and relieved transmission and distribution congestion.

This paper has proposed an approach to quantify the technical benefits of DG applications. The benefits have been determined based on a set of proposed indices.

It is shown that increasing the number of buses with connected DG has a positive effect on the improvement of the voltage profile and the reduction of line losses but increases the line loading and has negative effect on the line capacity release. Also, selecting the buses which are dispersed in the region, improves the voltage profile index, reduces line losses and increases the line capacity release. From the amount of generation point of view, increasing of DGs generation improves VPII, reduces line losses and LCRI increment is proportional to DGs generation increment.

As expected, DG rating plays a vital role in determining the amount of voltage profile improvement and environmental impact reduction. However, this trend may not always be applicable to line-loss reduction because the amount of line-loss reduction may actually decrease in some scenarios.
The location of DG is also significant to both voltage profile improvement and line-loss reduction.

Quantitative studies shows that the substitution of only 132 MW centralized conventional generations by DGs, would prevent the emission of 84145 ton $\mathrm{CO} 2,1263$ ton NOx and 455 ton SOx in each year.

\section{REFERENCES}

[1] P. Chiradeja and R. Ramakumar, "A review of distributed generation and storage," in Proc. 1998 Frontiers of Power Conf., pp. VIII 1-VIII 11.

[2] R. Ramakumar and P. Chiradeja, "Distributed generation and renewable energy systems", in Proc. 37th Intersociety Energy Conversion Engineering Conference (IECEC), pp. 716-724, 2002.

[3] L.T.Borges, M.Falcao," Impact of Distributed Generation Allocation and Sizing on Reliability, Losses and Voltage Profile", IEEE/PES Bologna Power Tech Conference, June 2003

[4] P. Chiradeja, "Benefit of distributed generation: A line loss reduction analysis", IEEE/PES Transmission and Distribution Conference \& 2005.

[5] P. Chiradeja, "Benefit of distributed generation: A line loss reduction analysis", IEEE/PES Transmission and Distribution Conference \& 2005.

[6] T. Hoff and D. S. Shugar, "The value of grid support photovoltaic in reducing distribution system losses" IEEE Transactions Energy Conversion, vol. 10, pp. 569-576, Sept. 1995.

[7] G. Joos, B. T. Ooi, D. McGillis, F.D. Galiana and R. Marceau, "The Potential of distributed generation to provide ancillary services", IEEE Power Engineering Society Summer Meeting, pp. 1762- 1767, 2000.

[8] P. Ajay-D-Vimal Raj1, S. Senthilkumar, J. Raja, S. Ravichandran and T. G. Palanivelu, "Optimization of Distributed Generation Capacity for Line Loss Reduction and Voltage Profile Improvement Using PSO", ELECTRA, Vol. 10, No. 2, pp. 41-48, 2008.

[9] F.Ochoa,P.Feltrin,G.P.Harrison,"Evalution Distributed Generation Impacts With a Multiopjective Index",IEEE Transaction on power Delivery, Vol. 21, No. 3, pp.14521458, July 2006.

[10] Víctor H. Méndez Quezada, Juan Rivier Abbad, and Tomás Gómez San Román, "Assessment of energy distribution losses for increasing penetration of distributed generation”, IEEE Transactions on Power Systems, Vol. 21, No. 2, pp. 533- 540, May 2006

[11] R. C. Dugan and S. K. Price, "Issues for distributed generations in the US," in Proc. IEEE Power Engineering Society Winter Meeting, vol. 1, Jan. 2002, pp. 121-126.

[12] E. Boes, Renewable power outlook, in Environmental Electric EnergyOpportunity for the Next Century, IEEE and EPRI, Washington, DC,Apr. 1998. paper presented at the Vision-21.

[13] Iran ministry of energy reports, 2007

Table VI. Decrement of GHGs Emission by substituting existing power plants with DGs

\begin{tabular}{|c|c|c|c|c|c|}
\hline $\begin{array}{c}\text { Scenario } \\
\text { No. }\end{array}$ & $\begin{array}{c}\text { Installed } \\
\text { DG }\end{array}$ & $\begin{array}{c}\text { MWh/ } \\
\text { Year }\end{array}$ & $\begin{array}{c}\text { Decreased } \\
\mathbf{C O}_{2} \\
(\mathbf{K g} / \mathbf{y e a r})\end{array}$ & $\begin{array}{c}\text { Decreased } \\
\text { NOx } \\
\text { (Kg/year) }\end{array}$ & $\begin{array}{c}\text { Decreased } \\
\text { SOx } \\
(\mathbf{K g} / \text { year })\end{array}$ \\
\hline 1 & 26 & $75,920.00$ & $13,619,441$ & 73,794 & 204,528 \\
\hline 2 & 53 & $154,760.00$ & $27,762,706$ & 150,427 & 416,923 \\
\hline 3 & 132 & $385,440.00$ & $69,144,852$ & 374,648 & $1,038,375$ \\
\hline
\end{tabular}

Decreasing rate of Nox $(\mathrm{gr} / \mathrm{kWh})$

Decreasing rate of Sox $(\mathrm{gr} / \mathrm{kWh})$

Decreasing rate of $\mathrm{Co} 2(\mathrm{gr} / \mathrm{kWh})$
0.972

2.694

179.392 
Table VII. Decrement of GHGs Emission by substituting existing power plants with DGs caused by loss reduction in the case 3

\begin{tabular}{|c|c|l|l|l|l|}
\hline Scenario No. & $\begin{array}{c}\text { Decreased loss } \\
(\mathbf{M W})\end{array}$ & MWh/Year & $\begin{array}{c}\text { Decreased } \\
\mathbf{C O}_{\mathbf{2}} \\
(\mathbf{k g} / \mathbf{y e a r})\end{array}$ & $\begin{array}{c}\text { Decreased } \\
\text { NOx } \\
(\mathbf{k g} / \mathbf{y e a r})\end{array}$ & $\begin{array}{c}\text { Decreased } \\
\mathbf{\text { SOx }} \\
(\mathbf{k g} / \mathbf{y e a r})\end{array}$ \\
\hline 1 & 6.21 & $18,133.20$ & $3,252,951$ & 17,625 & 48,851 \\
\hline 2 & 12.15 & $35,478.00$ & $6,364,469$ & 34,485 & 95,578 \\
\hline 3 & 28.64 & $83,628.80$ & $15,002,338$ & 81,287 & 225,296 \\
\hline
\end{tabular}

Table VIII. Total decrement of GHGs Emission by substituting existing power plants with DGs

\begin{tabular}{|c|c|c|c|}
\hline Scenario No. & $\begin{array}{c}\text { Total decreased } \text { CO }_{\mathbf{2}} \\
\text { (Ton/year) }\end{array}$ & $\begin{array}{c}\text { Total decreased NOx } \\
\text { (Ton/year) }\end{array}$ & $\begin{array}{c}\text { Total decreased SOx } \\
\text { (Ton/year) }\end{array}$ \\
\hline 1 & 16,872 & 91 & 253 \\
\hline 2 & 34,127 & 184 & 512 \\
\hline 3 & 84,145 & 455 & 1,263 \\
\hline
\end{tabular}

